\title{
Rainfall and Temperature Scenario for Bangladesh
}

\author{
Md. Nazrul Islam ${ }^{*} \S$ \\ SAARC Meteorological Research Centre, E-4/C Agargaon, Dhaka-1207, Bangladesh
}

\begin{abstract}
A regional climate model named Providing REgional Climates for Impacts Studies (PRECIS) adapted in generating rainfall scenarios for the SAARC (South Asian Association for Regional Cooperation) region. At first, PRECIS generated rainfall scenario is calibrated with ground-based observed rainfall during baseline period (1961-1990) in Bangladesh. The regression coefficients obtained through calibration are utilized for validation of PRECIS simulated rainfall during 2000-2006. PRECIS overestimated rainfall by $12.37 \%, 1.58 \%, 10.81 \%, 4.79$ and $13.18 \%$ in $2000,2002,2003,2005$ and 2006 respectively. It underestimated by $0.64 \%$ and $10.84 \%$ in 2001 and 2004 respectively. On an average, PRECIS overestimated about $4.47 \%$ of surface rainfall. Better performance of PRECIS through validation encourages employing it in rainfall forecasting for Bangladesh. In the second step, rainfall and temperature forecast for Bangladesh is experimentally obtained for 2010-2020. This work discloses that the PRECIS simulated rainfall and temperature are not directly useful in application purposes. However, after performing calibration, acceptable result is obtained in estimating annual rainfall in Bangladesh with correlation coefficient is 0.90 . Change of rainfall is forecasted from $-0.99 \%$ (in 2013 ) to $5.3 \%$ (2018) for Bangladesh during 2010 - 2020.
\end{abstract}

Keywords: Rainfall forecast, climate change, regional climate model, simulation, calibration, validation, Bangladesh.

\section{INTRODUCTION}

Eight South Asian nations- Afghanistan, Bangladesh, Bhutan, India, Maldives, Nepal, Pakistan and Sri Lanka, have an economic and political body, the South Asian Association for Regional Cooperation (SAARC). The SAARC region is the most vulnerable to climate change that is seriously affecting agricultural production, diminishing natural resources and limiting development options for the future in this region. The World Bank climate change experts' opinion is that the poorest of the poor in South Asia are the most affected by climate change. The impact of higher temperatures, more extreme weather events such as floods, cyclone, severe drought, and sea level rise are already being felt in South Asia, and will continue to intensify [1-3]. Climate change is recognized as the greatest long-term threat to the SAARC region. The economic impact of climate change, rising food prices and assessment of food security are key issues to discuss. It is accounted that in the SAARC countries $21 \%$ of world population resides on only $4 \%$ of the world's total physical area. In this connection proper planning and judicious management of water resources are essential for this region. Long-term planning is impossible without any idea of the change of climate to be happened in future. Climate models are the main tools available for developing projections of climate change in the future $[4,5]$. In recent years, Atmosphere-Ocean General Circulation Models (AOGCMs) have been used to predict the climatic consequences of increasing atmospheric concentrations of

*Address correspondence to this author at the SAARC Meteorological Research Centre, E-4/C, Agargaon, Dhaka-1207, Bangladesh;

Tel: +88-01715573040; Fax: +88-02-9144373;

E-mails:mnislam@phy.buet.ac.bd, nazrul64@gmail.com

${ }^{\S}$ The author is on leave from the Department of Physics, BUET, Bangladesh". greenhouse gases $[6,7]$. These predictions may be adequate for areas where the terrain is reasonably flat, uniform and away from coasts. However, in SAARC areas where coasts and mountains have significant effects on weather and therefore scenarios based on global models are unable to capture the local-level details needed for assessing impacts at national and regional scales. Projections using global circulation model (GCM) showing that sea and air temperatures will continue to increase, sea level is rising, intense storms and rainfall will become more frequent. Climate is a driver for almost every natural resource management issue being tackled by regional bodies, and climate change will have farreaching impacts on many ecological, hydrological and resource-degrading processes. The highest horizontal resolution of any AOGCM published is around $300 \mathrm{~km}$ [8]. Yet in order to assess potential impacts of climate change, regional information at a scale of $100 \mathrm{~km}$ or finer (typically around $50 \mathrm{~km}$ ) is needed [9-12]. Regional Climate Model (RCM), therefore, is the best tool for dynamical downscaling of climate features in case of obtaining detailed information for a particular region $[13,14]$. Downscaling from RCM outputs are important in understanding the local phenomena.

The Intergovernmental Panel on Climate Change (IPCC) predicted that Bangladesh was on course to lose $17 \%$ of its land and $30 \%$ of its food production by 2050 . Bangladesh has already begun to feel the effects of climate change as flood periods have become longer and cyclones cause greater devastation. This paper examines the calibration and validation of rainfall climatology in Bangladesh derived from a RCM called Providing REgional Climates for Impact $\underline{\text { Studies }}$ (PRECIS) for baseline period (1961-1990) and 2000-2006 respectively. Calibration and validation for temperature is also performed for Bangladesh. Finally, projections for rainfall and temperature are made for 2010-2020 in Bangladesh. 


\section{METHODOLOGY}

The Hadley Centre of United Kingdom has developed PRECIS, a regional climate model (RCM) system which can be run to generate climate change scenarios. The aim of PRECIS is to allow developing countries, or groups of developing countries, to generate their own national scenarios of climate change to use in impacts studies. It is a hydrostatic, primitive equation grid point model containing 19 levels described by a hybrid vertical coordinate $[15,16]$. In the first step, PRECIS was run with $50 \mathrm{~km}$ horizontal resolution for the baseline period (1961-1990) to calibrate PRECIS outputs with observed datasets. The model domain is selected $65-103^{\circ} \mathrm{E}$ and $6-35^{\circ} \mathrm{N}$ to cover entire SAARC region. Calibration and validation of PRECIS is considered for Bangladesh as to understand the model performance in simulating climate parameters. Once the reasonable result is to be obtained, PRECIS can be used to accomplish similar work for other member countries. Surface rainfall collected by Bangladesh Meteorological Department (BMD) throughout the country (Fig. 1) has been used for the calibration of PRECIS generated rainfall and temperature. When the coverage of Bangladesh is gridded at $0.5^{\circ} \times 0.5^{\circ}$ resolutions, a number of grids are found which do not contain any observation site. For the application of PRECIS for climate change impact studies in Bangladesh, it is important to find out the appropriate calibration method. Having this in mind, analyses have been performed on point-to-point basis [17]. In this procedure, observed data at a particular site is considered as the representative of that location. Grid value of the model data is compared with the observed data representing that grid. If more than one observation sites exist within a grid, average value of all the observational sites is considered as representative value for that grid. Rain-gauge daily rainfall data collected by BMD are processed to obtain monthly, seasonal, annual, decadal and long-term values. The model data of rainfall and temperature are extracted at 27 observational sites of BMD and then are converted to monthly, seasonal, annual, decadal and long-term values. Averages for 27 stations are considered as country. Through the regression expression the slopes and constants values are assigned from model and observed rainfall for the baseline period. Estimated rainfall is obtained from model generated scenarios with the help of slopes and constants values. This estimated rainfall is useful for validation of PRECIS RCM in Bangladesh. Similarly, calibration and validation is completed for maximum and minimum temperature in Bangladesh.

In the second step, PRECIS was run $(50 \mathrm{~km} \times 50 \mathrm{~km}$ resolution) for the year 2000-2020. The Special Report on Emissions Scenarios (SRES) A2 of ECHAM4 is used as model input. Using the slopes and constants, model generated rainfall and temperatures are validated for 2000-2006. The TRMM (Tropical Rainfall Measuring Mission) version 6 3B42 3-hourly data products are also utilized to understand the distribution of model generated rainfall. TRMM obtained rainfall can be considered as ground-truth amount especially for Bangladesh where it was calibrated with rain-gauge data [18]. The future scenario obtained by PRECIS for 2009 is used to prepare rainfall forecast in Bangladesh for the year 2009. Regression coefficients are utilized with 2009 rainfall scenario for the forecast purpose in different months and at different observational sites. The time series of rainfall from
2010 to 2020 is projected in Bangladesh. In the same way, temperature analysis is also completed. The change of rainfall and temperature are obtained from model simulation reference to historical observation during 1961-1990 which is taken as normal.

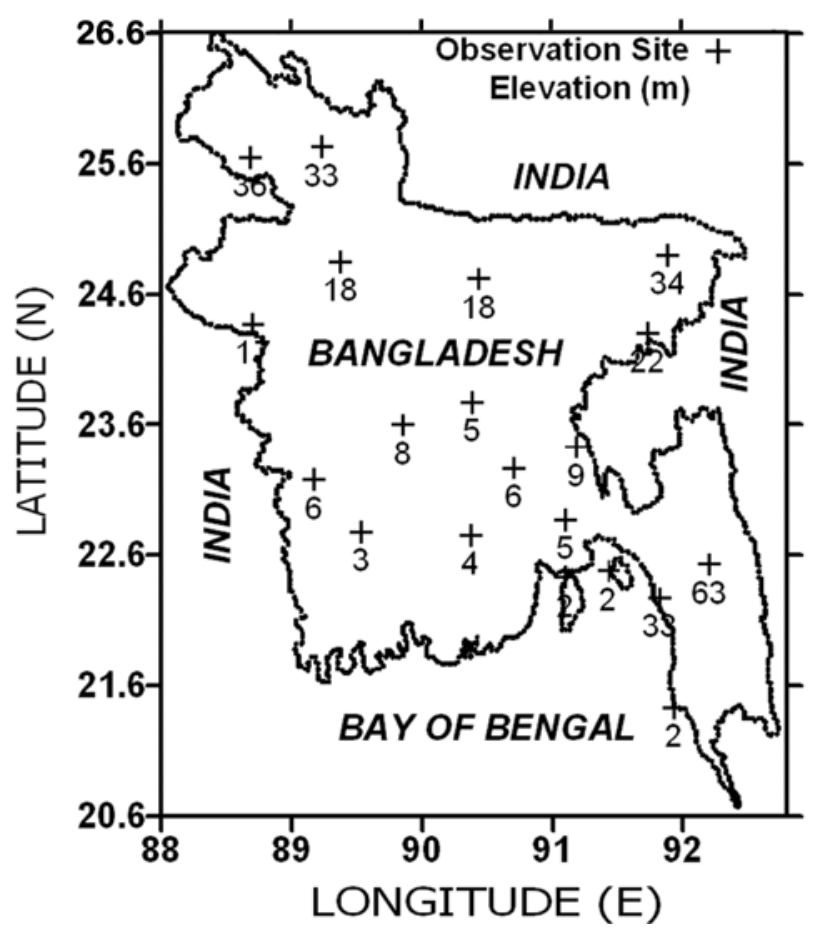

Fig. (1). The BMD observational site (plus mark) with elevation in $\mathrm{m}$ (below plus mark).

\section{RESULTS}

\section{Simulation of Rainfall in SAARC Domain}

PRECIS generated present climate (1961-1990) in the SAARC region is shown in Fig. (2). There is a clear heavy rainfall belt observed along the Western Ghat of India, along Nepal-Bhutan region and along northeastern side of the Bay of Bengal. Heavy rainfall is also observed in the northeastern part of Bangladesh which is actually located in the slope of Shillong Hill of India. These features are very common and seem quite reasonable with rainfall climatology of this region.

\section{Calibration of Rainfall in Bangladesh}

PRECIS simulated rainfall need to be calibrated with the observed data; otherwise model performance may not be well understood. In this paper calibration of rainfall for Bangladesh (averages from all stations over the country) is taken as a pilot study. In order to calibrate model simulated rainfall with rain-gauge rainfall in Bangladesh, model rainfall are processed for 27 stations and compared with raingauge amounts in seasonal scales (Fig. 3). Model overestimated pre-monsoon rainfall and underestimated monsoon rainfall with amounts in post-monsoon and dry periods is almost closer. The similar result is reported by Islam et al. [17]. To find an adjustment between model and observed 
rainfall amounts the following regression equation is proposed:

$R F_{\text {estimated }}=$ constant + slope $\times R F_{\text {scenario }}$

where $R F_{\text {estimated }}$ is the rainfall to be projected and $R F_{\text {scenario }}$ is the PRECIS simulated rainfall scenario. The regression coefficients such as constant and slope are obtained with the help of both model and observed rainfall in different months and at different observational sites. The constant values vary from month-to-month and also from place-to-place. Similarly, slope values vary from month-to-month and also from place-to-place with both positive and negative sign as discussed later on.

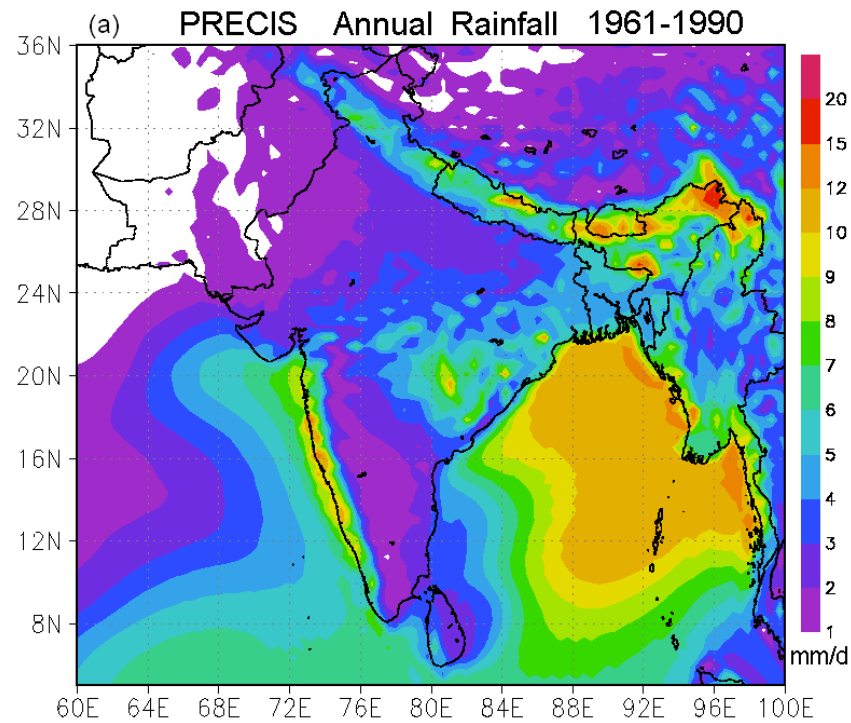

Fig. (2a). PRECIS generated annual rainfall $(\mathrm{mm} / \mathrm{d})$ averages for baseline period (1961-1990).

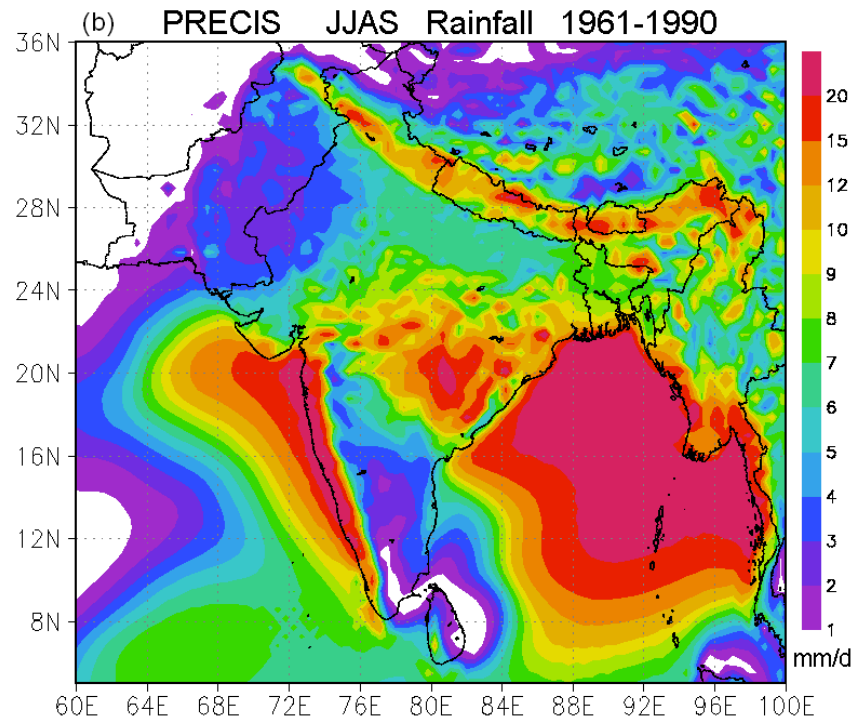

Fig. (2b). PRECIS generated monsoon period (JJAS) rainfall (m/d) averages for baseline period (1961-1990).

\section{Validation of Rainfall in Bangladesh}

Monsoon rainfall is much important for the SAARC region; therefore, rainfall averages from June to September (JJAS) of 2002 is presented in Fig. (4). Monsoon rainfall $(\mathrm{mm} / \mathrm{d})$ derived from PRECIS and TRMM V6 3B42 are shown in Fig. (4). Monsoon rainfall simulated by PRECIS is much more consistent with TRMM observed rainfall. It is almost below $1 \mathrm{~mm} / \mathrm{d}$ in most parts of Afghanistan and Pakistan which are well simulated by the model. Also the signal of heavy rainfall in the Western Ghat of India, central part of Nepal and northeastern part of Bangladesh are also well simulated. This indicates that PRECIS can simulate the seasonal rainfall with a better spatial distribution. Because the PRECIS output is calibrated with rain-gauge rainfall, therefore, model validation is performed against rain-gauge rainfall, however, TRMM datasets provides clear insight for the entire SAARC domain which is not possible from rain-gauge datasets.

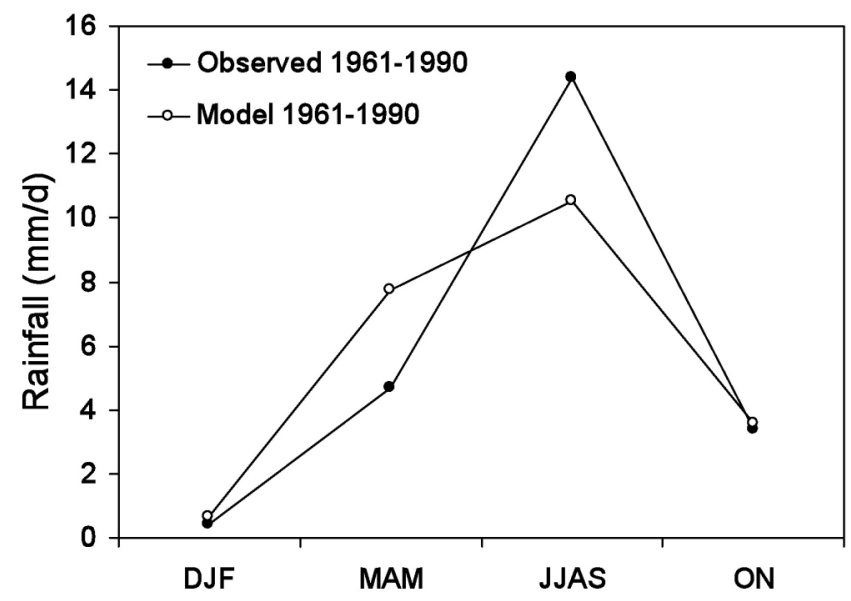

Fig. (3). Seasonal distribution of rainfall obtained from Observation and PRECIS model.

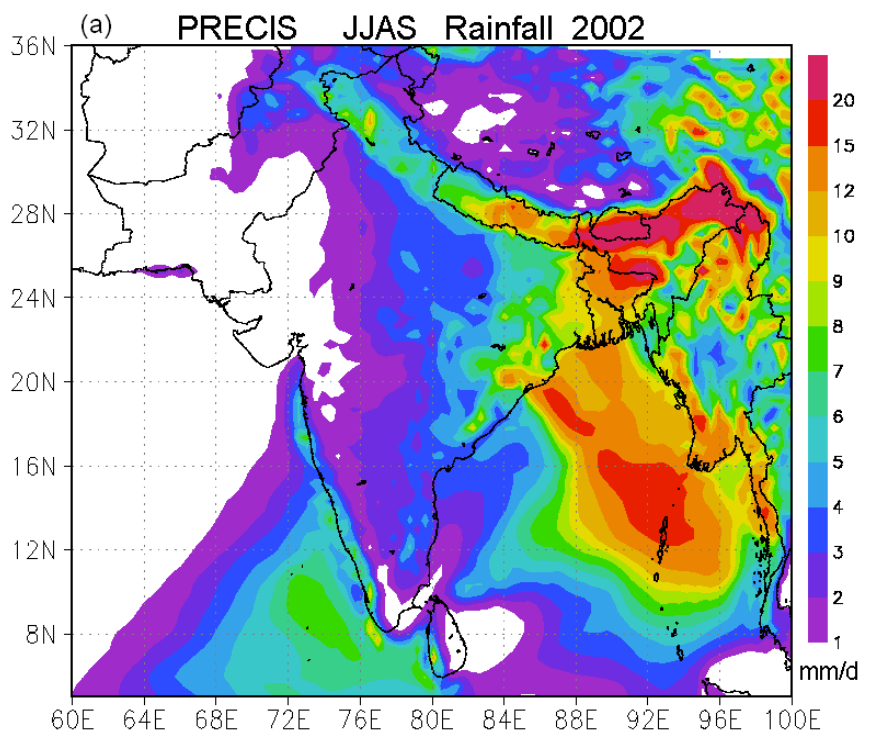

Fig. (4a). The monsoon (JJAS) rainfall obtained from PRECIS for 2002.

With the help of regression slopes and constants, PRECIS outputs are validated with observed rainfall for Bangladesh. As an example, model simulated scenario (without calibration), estimated (with calibration), observed and normal (observed baseline period) rainfall for 2002 is shown in Fig. (5). Hence, utilization of regression coefficients improved a lot the estimated value that influenced model outputs to be very close to observed amount which follows the historical pattern. 
Without calibration, model generated scenario directly does not match well with the observed amount. In annual scale, the estimated amount is surprisingly coincided with the observed value. This indicates that rainfall was surplus (observed) in 2002 and that information is well captured by the PRECIS model. Such type of information in advance is very much helpful for planners in mitigating food crisis, water scarcity and other kind of disaster management of the country.

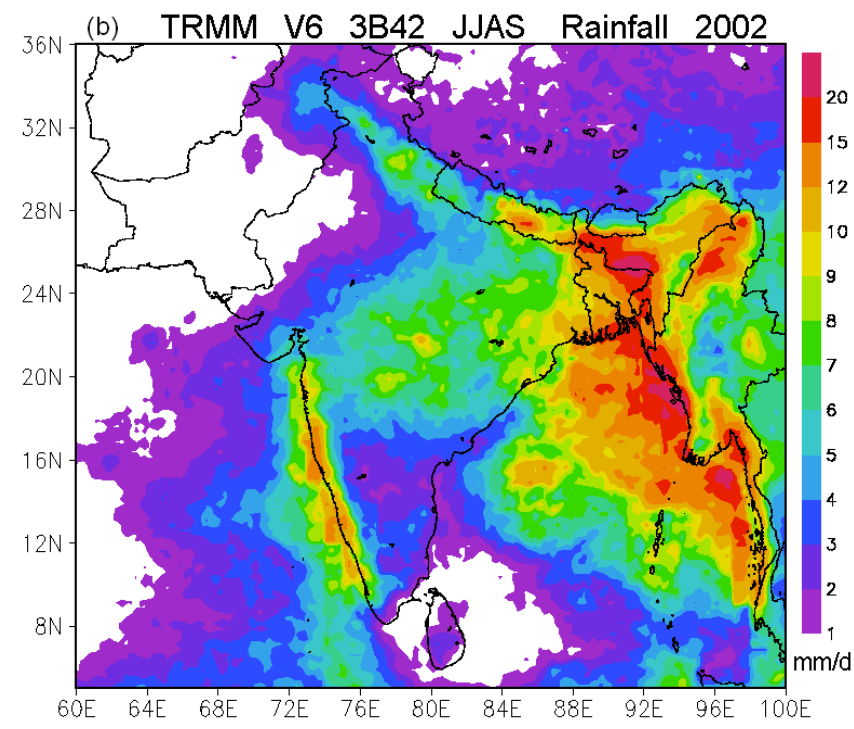

Fig. (4b). The monsoon (JJAS) rainfall obtained from TRMM V6 data for 2002 .

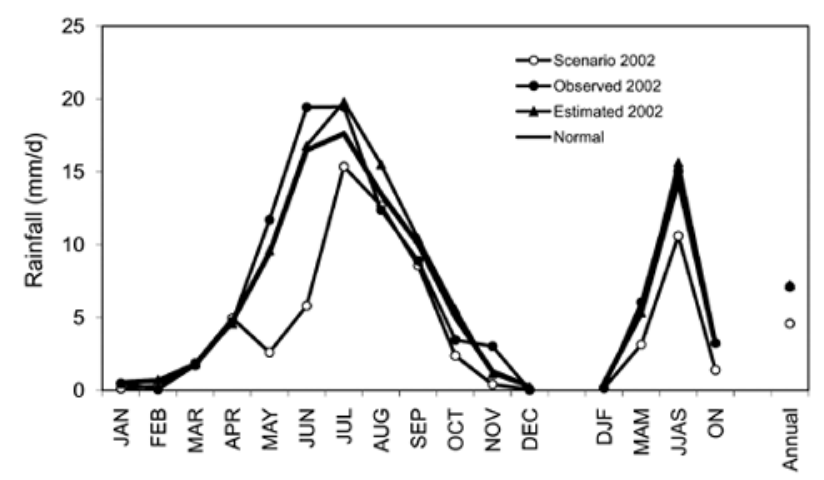

Fig. (5). Annual rainfall (mm/d) distribution obtained from observation, model simulation (Scenario), model projection (Estimated) and observed baseline period (Normal).

Model simulated and calibrated rainfall $(\mathrm{mm} / \mathrm{d})$ for 2000 2006 is shown in Fig. (6) along with observed amount. Model overestimated rainfall in 2000, 2002, 2003, 2005 and 2006 whereas it underestimated in 2004. Model rainfall in 2001 is very close to the observed amount. This inter-annual variation in simulating rainfall is not unexpected because model can not simulate any meteorological parameter in $100 \%$ accurately. The question arises how much perfect the PRECIS simulation in Bangladesh and how it can be utilized in application purposes? To answer these questions model performance is calculated: performance is the difference of model and observed value divided by observed amount in percentage. PRECIS overestimated $12.37 \%, 1.58 \%, 10.81 \%$,
4.79 and $13.18 \%$ in 2000, 2002, 2003, 2005 and 2006 respectively. It underestimated $0.64 \%$ and $10.84 \%$ in 2001 and 2004 respectively. In an average PRECIS overestimated about $4.47 \%$. It seems that the PRECIS performance is quite reasonable because about $4.47 \%$ (varies from $-10.84 \%$ to $13.18 \%$ ) error may be considered in long-term forecasting by using a climate model. One can calculate correlation coefficient between monthly model and observed rainfall which lies within 0.87 to 0.97 . Then knowing the uncertainties, the forecast may be utilized with percentage of uncertainties that may be helpful for planners to do long-term preparedness.

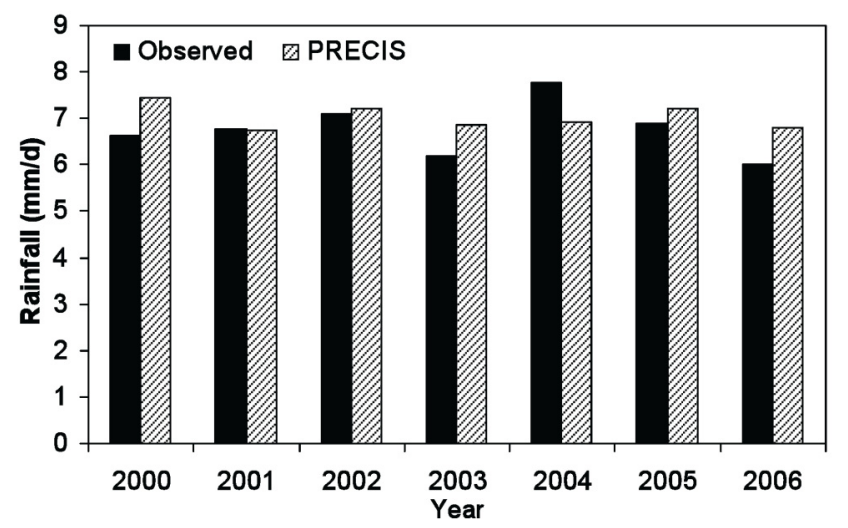

Fig. (6). Validation of PRECIS simulated rainfall with observed amount for Bangladesh.

\section{Projection of Rainfall in SAARC Region}

PRECIS simulated annual and monsoon period rainfall $(\mathrm{mm} / \mathrm{d})$ scenarios for the SAARC domain for 2009 is shown in Fig. (7). Large amount of rainfall is expected along the belt of Nepal and Bhutan including Shillong Hills of India. The validation of model rainfall with ground-truth value over Bangladesh, it is observed that PRECIS generated rainfall scenarios are not directly useful in application purposes.

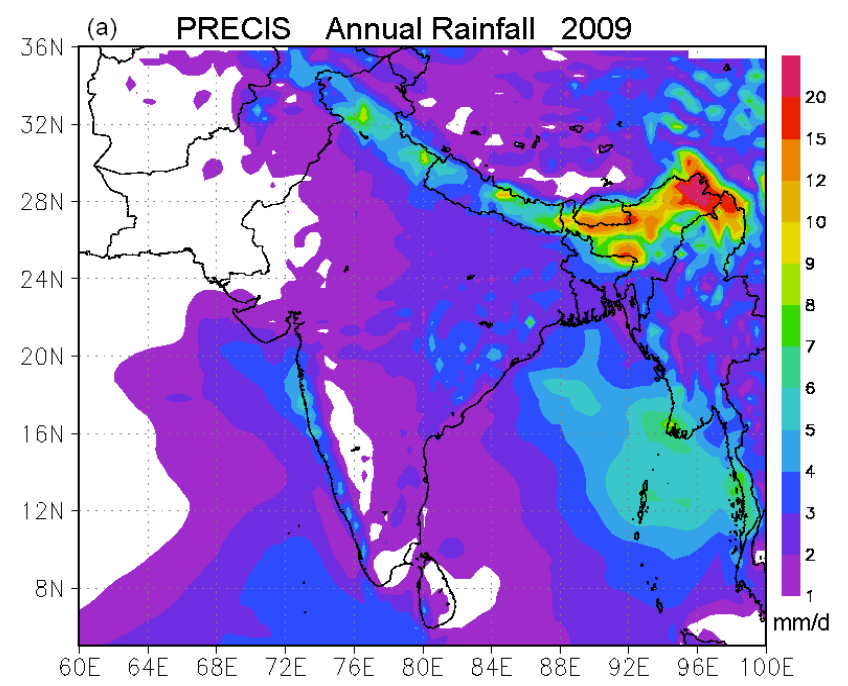

Fig. (7a). Projection of annual rainfall $(\mathrm{mm} / \mathrm{d})$ in the SAARC domain for 2009.

\section{Projection of Rainfall in Bangladesh}

PRECIS generated daily rainfall extracted at each observational site is obtained for each month. As an example, 


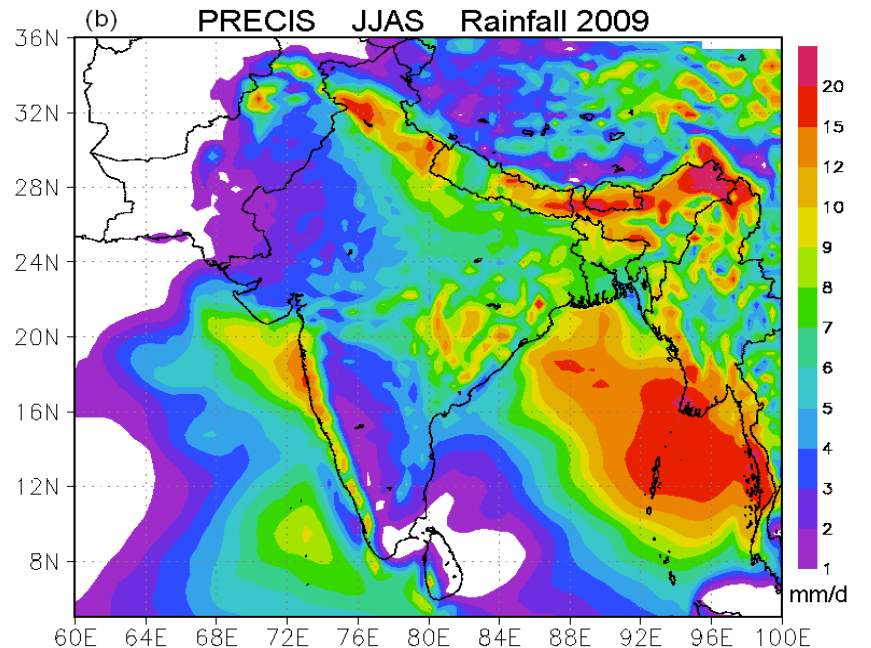

Fig. (7b). Projection of monsoon period (JJAS) rainfall $(\mathrm{mm} / \mathrm{d})$ in the SAARC domain for 2009. model generated monthly rainfall $(\mathrm{mm} / \mathrm{d})$ in all stations through January to February of 2009 is presented in Table $\mathbf{1}$. Averages of rainfall for all stations over Bangladesh are considered as country rainfall. The normal (average from 19611990) amounts are also incorporated to understand the surplus or deficit of rainfall in different months of the year 2009. For the country (averages for all stations), model simulated rainfall (not-calibrated, Table 1) amounts are somehow unrealistic with historical normal. Model simulated amounts are low with reference to normal, in some months simulated values are too low.

After performing calibration the projected rainfall is very closer to the historical value (calibrated, Table 2). Again the necessity of calibration is well understood through this research work and this is very essential in using model generated rainfall in application purposes. Once the calibrated and reliable model outputs are available for the planners, the overall improvement will definitely helpful for the end users and sustainable development of the country.

Table 1. Model Simulated Monthly Rainfall in mm/d (Not-Calibrated) at Different Location over Bangladesh in 2009

\begin{tabular}{|c|c|c|c|c|c|c|c|c|c|c|c|c|}
\hline & JAN & FEB & MAR & APR & MAY & JUN & JUL & AUG & SEP & OCT & NOV & DEC \\
\hline Barishal & 0.00 & 0.13 & 0.83 & 0.38 & 0.41 & 4.60 & 7.63 & 12.48 & 2.71 & 0.19 & 0.04 & 0.00 \\
\hline Bhola & 0.01 & 0.13 & 0.98 & 0.21 & 0.49 & 5.11 & 7.19 & 12.12 & 1.80 & 0.11 & 0.02 & 0.01 \\
\hline Bogra & 0.36 & 0.03 & 4.07 & 3.45 & 2.60 & 8.39 & 10.57 & 11.56 & 5.91 & 0.00 & 0.14 & 0.00 \\
\hline Chandpur & 0.00 & 0.10 & 1.23 & 0.32 & 0.41 & 4.68 & 6.17 & 9.71 & 2.25 & 0.16 & 0.03 & 0.00 \\
\hline Chittagong & 0.06 & 0.76 & 0.37 & 0.22 & 1.23 & 7.12 & 4.80 & 5.67 & 0.88 & 0.02 & 0.04 & 0.01 \\
\hline Comilla & 0.03 & 0.07 & 2.59 & 0.63 & 0.48 & 5.21 & 7.13 & 9.65 & 2.78 & 0.21 & 0.05 & 0.01 \\
\hline Cox's Bazar & 0.06 & 0.53 & 0.36 & 0.18 & 0.98 & 9.12 & 2.22 & 4.43 & 0.56 & 0.12 & 0.07 & 0.05 \\
\hline Dhaka & 0.19 & 0.09 & 2.87 & 2.83 & 1.07 & 7.12 & 8.65 & 12.10 & 5.52 & 0.10 & 0.29 & 0.00 \\
\hline Dinajpur & 0.02 & 0.01 & 3.24 & 3.14 & 2.48 & 6.97 & 13.40 & 12.60 & 5.98 & 0.01 & 0.38 & 0.00 \\
\hline Faridpur & 0.07 & 0.07 & 1.26 & 0.96 & 0.44 & 5.58 & 8.62 & 10.94 & 4.10 & 0.09 & 0.25 & 0.00 \\
\hline Hatiya & 0.02 & 0.18 & 1.42 & 0.25 & 0.58 & 5.89 & 4.27 & 7.37 & 1.07 & 0.05 & 0.03 & 0.03 \\
\hline Ishurdi & 0.46 & 0.05 & 0.82 & 1.23 & 1.54 & 5.63 & 9.27 & 10.41 & 5.55 & 0.05 & 0.05 & 0.00 \\
\hline Jessore & 0.02 & 0.09 & 0.69 & 0.37 & 0.23 & 4.20 & 8.55 & 11.52 & 3.84 & 0.10 & 0.17 & 0.00 \\
\hline Khepupara & 0.01 & 0.12 & 0.46 & 0.18 & 0.40 & 4.53 & 8.70 & 14.72 & 2.42 & 0.14 & 0.03 & 0.01 \\
\hline Khulna & 0.01 & 0.14 & 0.45 & 0.13 & 0.23 & 3.66 & 8.69 & 12.20 & 3.52 & 0.12 & 0.10 & 0.00 \\
\hline Kutubdia & 0.09 & 0.94 & 0.25 & 0.24 & 1.18 & 7.76 & 2.48 & 4.16 & 0.57 & 0.08 & 0.06 & 0.04 \\
\hline Maijdi Court & 0.00 & 0.08 & 1.76 & 0.27 & 0.51 & 5.40 & 7.24 & 10.17 & 2.39 & 0.15 & 0.02 & 0.01 \\
\hline Mymensingh & 0.12 & 0.22 & 8.60 & 13.68 & 4.07 & 10.87 & 8.17 & 10.01 & 5.20 & 0.01 & 0.10 & 0.02 \\
\hline Patuakhali & 0.01 & 0.12 & 0.46 & 0.18 & 0.40 & 4.53 & 8.70 & 14.72 & 2.42 & 0.14 & 0.03 & 0.01 \\
\hline Rajshahi & 0.83 & 0.04 & 1.22 & 1.28 & 1.87 & 7.13 & 9.86 & 10.90 & 5.64 & 0.04 & 0.05 & 0.01 \\
\hline Rangamati & 0.01 & 0.07 & 0.53 & 0.20 & 0.43 & 9.02 & 5.97 & 8.06 & 3.12 & 0.05 & 0.03 & 0.01 \\
\hline Rangpur & 0.03 & 0.01 & 4.97 & 6.30 & 3.25 & 8.78 & 12.50 & 12.68 & 6.34 & 0.01 & 0.33 & 0.00 \\
\hline Sandwip & 0.04 & 0.23 & 1.46 & 0.40 & 0.77 & 5.93 & 4.57 & 7.83 & 1.38 & 0.06 & 0.07 & 0.06 \\
\hline Sitakunda & 0.08 & 0.05 & 2.59 & 0.70 & 0.53 & 6.16 & 9.31 & 11.88 & 3.74 & 0.28 & 0.09 & 0.08 \\
\hline Srimongal & 0.08 & 0.06 & 6.91 & 6.93 & 1.48 & 7.66 & 7.84 & 9.41 & 4.10 & 0.13 & 0.22 & 0.03 \\
\hline Sylhet & 0.23 & 0.65 & 25.98 & 30.80 & 11.26 & 12.57 & 12.44 & 12.97 & 7.86 & 0.40 & 0.41 & 0.07 \\
\hline Teknaf & 0.02 & 0.16 & 0.13 & 0.09 & 0.77 & 14.54 & 6.23 & 7.87 & 0.83 & 0.06 & 0.03 & 0.02 \\
\hline Barishal & 0.11 & 0.19 & 2.83 & 2.80 & 1.49 & 6.97 & 7.82 & 10.30 & 3.43 & 0.11 & 0.11 & 0.02 \\
\hline Bhola & 0.51 & 0.66 & 1.74 & 4.70 & 9.32 & 16.48 & 17.39 & 13.39 & 10.01 & 4.96 & 1.28 & 0.25 \\
\hline Country & 0.11 & 0.19 & 2.83 & 2.80 & 1.49 & 6.97 & 7.82 & 10.30 & 3.43 & 0.11 & 0.11 & 0.02 \\
\hline Normal & 0.51 & 0.66 & 1.74 & 4.70 & 9.32 & 16.48 & 17.39 & 13.39 & 10.01 & 4.96 & 1.28 & 0.25 \\
\hline
\end{tabular}




\section{Annual to Seasonal Projection of Rainfall in Bangladesh}

Annual cycle of model projected rainfall in Bangladesh for 2010 to 2020 is shown in Fig. (8) with normal (averages for 1961-1990) amounts. Projected rainfall will follow the historical trend with some variations in some months in different years. In most of the years, rainfall will surplus in April, July, August and September. However, deficit of rainfall will also be observed in some months.

Fig. (9) shows the monthly to seasonal and annual scale rainfall projection for Bangladesh in 2009 (Fig. 9a) and 2020 (Fig. 9b). The amounts are obtained incorporating the calibration procedure. The historical trend of normal is also plotted in understanding the change of rainfall in coming years. It is very obvious that the rainfall over Bangladesh in 2009 will follow the historical trend with deficit in April $(0.62$ $\mathrm{mm} / \mathrm{d}$ or $13.08 \%$ ) and surplus in August $(1.37 \mathrm{~mm} / \mathrm{d}$ or $10.19 \%)$ and in October (1.05 or $20.90 \%)$. In seasonal scale,

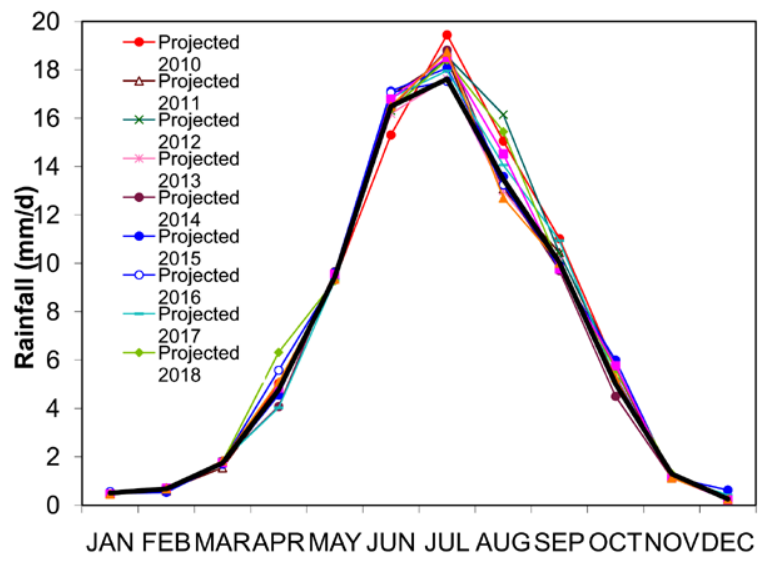

Fig. (8). Annual cycle of projected rainfall $(\mathrm{mm} / \mathrm{d})$ in Bangladesh with normal.

Table 2. Projected Rainfall in $\mathbf{m m} / \mathrm{d}$ (Calibrated) at Different Location over Bangladesh in 2009

\begin{tabular}{|c|c|c|c|c|c|c|c|c|c|c|c|c|}
\hline & JAN & FEB & MAR & APR & MAY & JUN & JUL & AUG & SEP & OCT & NOV & DEC \\
\hline Barishal & 0.27 & 0.69 & 1.73 & 2.96 & 6.95 & 11.14 & 12.73 & 17.49 & 9.97 & 7.73 & 0.84 & 0.36 \\
\hline Bhola & 0.57 & 2.55 & 4.82 & 7.08 & 19.15 & 13.22 & 12.17 & 9.48 & 5.08 & 4.75 & 0.05 & 0.30 \\
\hline Bogra & 0.45 & 0.42 & 0.77 & 2.27 & 7.34 & 9.11 & 19.22 & 4.20 & 8.13 & 4.26 & 0.50 & 0.06 \\
\hline Chandpur & 0.55 & 0.42 & 2.33 & 4.55 & 12.20 & 8.97 & 13.30 & 14.04 & 9.06 & 6.66 & 1.18 & 0.09 \\
\hline Chittagong & 0.41 & 0.44 & 1.81 & 3.28 & 4.79 & 18.17 & 26.91 & 17.02 & 8.95 & 6.65 & 2.04 & 0.37 \\
\hline Comilla & 0.29 & 0.38 & 1.41 & 4.52 & 9.17 & 11.19 & 14.18 & 9.69 & 8.85 & 6.09 & 1.00 & 0.13 \\
\hline Cox's Bazar & 0.47 & 0.70 & 3.09 & 7.04 & 24.91 & 38.08 & 14.39 & 10.97 & 7.80 & 3.65 & 0.34 & 0.19 \\
\hline Dhaka & 0.31 & 0.70 & 1.61 & 5.00 & 12.27 & 11.97 & 11.95 & 9.85 & 9.59 & 4.86 & 1.01 & 0.29 \\
\hline Dinajpur & 0.69 & 0.27 & 1.19 & 2.01 & 6.70 & 10.25 & 21.73 & 14.60 & 9.96 & 3.06 & 0.21 & 0.07 \\
\hline Faridpur & 0.28 & 0.84 & 1.74 & 3.70 & 7.75 & 13.46 & 12.61 & 11.20 & 7.41 & 4.15 & 0.90 & 0.20 \\
\hline Hatiya & 0.47 & 0.69 & 2.11 & 4.14 & 10.50 & 22.26 & 23.25 & 18.40 & 11.85 & 5.79 & 1.92 & 0.44 \\
\hline Ishurdi & 0.32 & 0.73 & 1.22 & 1.76 & 6.67 & 16.57 & 13.42 & 9.25 & 7.41 & 5.66 & 0.53 & 0.19 \\
\hline Jessore & 0.54 & 0.92 & 1.47 & 1.92 & 4.49 & 8.49 & 8.83 & 12.94 & 8.74 & 5.53 & 0.71 & 0.22 \\
\hline Khepupara & 0.64 & 0.89 & 1.43 & 2.14 & 6.26 & 9.22 & 21.30 & 15.41 & 14.58 & 7.44 & 1.83 & 0.23 \\
\hline Khulna & 0.19 & 0.76 & 1.54 & 2.28 & 6.19 & 9.89 & 11.41 & 11.15 & 9.89 & 4.94 & 0.75 & 0.09 \\
\hline Kutubdia & 0.26 & 0.39 & 2.55 & 2.56 & 2.28 & 35.59 & 16.30 & 6.28 & 6.80 & 5.43 & 2.18 & 0.21 \\
\hline Maijdi Court & 0.25 & 0.89 & 1.56 & 3.62 & 10.44 & 15.64 & 24.77 & 25.80 & 9.98 & 8.54 & 1.44 & 0.34 \\
\hline Mymensingh & 0.40 & 0.58 & 0.82 & 5.35 & 8.24 & 13.61 & 11.77 & 9.64 & 9.59 & 7.05 & 0.55 & 0.05 \\
\hline Patuakhali & 0.81 & 0.72 & 1.15 & 3.44 & 11.50 & 12.83 & 17.42 & 16.00 & 17.26 & 5.85 & 2.38 & 0.33 \\
\hline Rajshahi & 0.61 & 0.54 & 0.86 & 1.23 & 4.20 & 10.16 & 11.79 & 13.18 & 8.40 & 4.95 & 0.30 & 0.20 \\
\hline Rangamati & 0.43 & 0.56 & 1.38 & 3.86 & 6.58 & 17.23 & 18.17 & 14.23 & 10.26 & 6.13 & 1.84 & 0.50 \\
\hline Rangpur & 0.46 & 0.44 & 2.28 & 2.98 & 10.13 & 12.84 & 21.79 & 13.61 & 10.25 & 4.16 & 0.26 & 0.07 \\
\hline Sandwip & 0.49 & 0.55 & 1.47 & 5.27 & 10.21 & 20.63 & 28.19 & 22.21 & 9.25 & 7.33 & 1.47 & 0.40 \\
\hline Sitakunda & 0.32 & 0.44 & 1.53 & 5.45 & 12.91 & 17.22 & 23.94 & 35.92 & 8.12 & 11.60 & 1.79 & 0.09 \\
\hline Srimongal & 0.59 & 0.89 & 2.35 & 7.39 & 14.21 & 17.03 & 13.60 & 13.19 & 7.68 & 7.87 & 1.28 & 0.21 \\
\hline Sylhet & 0.84 & 2.20 & 4.25 & 13.63 & 19.01 & 31.38 & 26.56 & 20.62 & 15.88 & 8.02 & 1.00 & 0.15 \\
\hline Teknaf & 0.57 & 0.31 & 0.28 & 2.43 & 5.77 & 29.97 & 27.07 & 24.58 & 10.55 & 5.67 & 2.19 & 0.17 \\
\hline Barishal & 0.46 & 0.74 & 1.81 & 4.14 & 9.66 & 16.52 & 17.73 & 14.85 & 9.68 & 6.07 & 1.13 & 0.22 \\
\hline Bhola & 0.51 & 0.66 & 1.74 & 4.70 & 9.32 & 16.48 & 17.39 & 13.39 & 10.01 & 4.96 & 1.28 & 0.25 \\
\hline Country & 0.46 & 0.74 & 1.81 & 4.14 & 9.66 & 16.52 & 17.73 & 14.85 & 9.68 & 6.07 & 1.13 & 0.22 \\
\hline Normal & 0.51 & 0.66 & 1.74 & 4.70 & 9.32 & 16.48 & 17.39 & 13.39 & 10.01 & 4.96 & 1.28 & 0.25 \\
\hline
\end{tabular}


rainfall in 2009 will surplus in JJAS $(0.29 \mathrm{~mm} / \mathrm{d}$ or $2.03 \%)$ and $\mathrm{ON}(0.44 \mathrm{~mm} / \mathrm{d}$ or $14.02 \%)$ that influences to surplus it $0.14 \mathrm{~mm} / \mathrm{d}(2.09 \%)$ in annual scale. Rainfall in 2020 will also follow the historical pattern with surplus to $0.93 \%$ in annual scale. In this year surplus is calculated $2.08,0.55$ and $1.36 \%$ during pre-monsoon, monsoon and post-monsoon periods respectively with deficit to $3.93 \%$ during dry period. The fact is that the calibration makes the model simulated rainfall very reasonable reference to the historical normal.

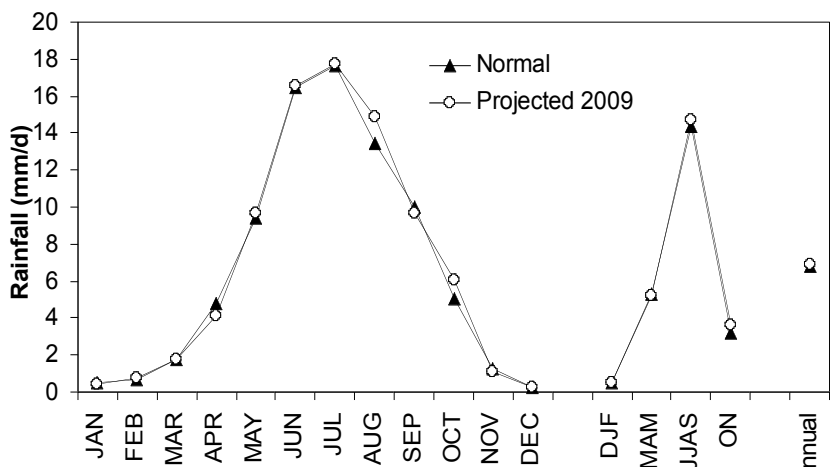

Fig. (9a). Rainfall projection over Bangladesh for the year 2009 with normal amount.

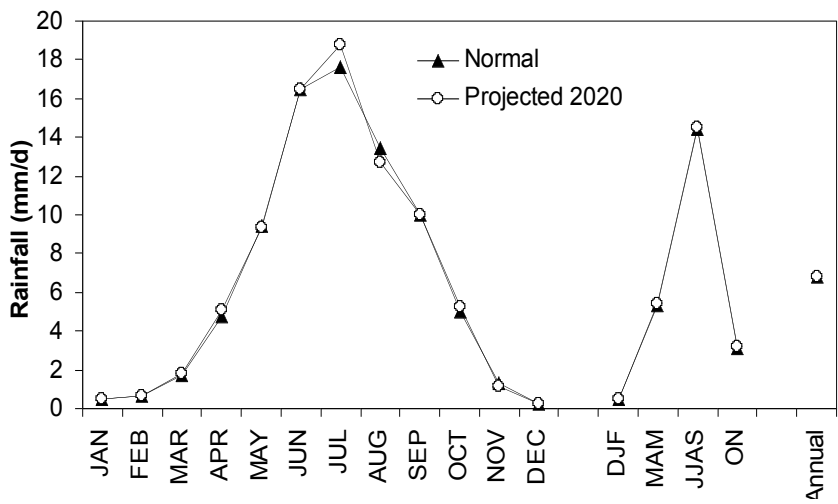

Fig. (9b). Rainfall projection over Bangladesh for the year 2020 with normal amount.

Projected rainfall $(\mathrm{mm} / \mathrm{d})$ during $2010-2020$ is presented in Table 3. The value of normal is also given to understand the change of rainfall in coming years.

\section{Annual to Seasonal Projection of Temperature in Bangladesh}

Temperature is an important parameter in understanding global warming. Mainly, the change of rainfall and temperature are considered as the measure of climate change in a particular region. Similar to the rainfall, calibration and validation of both maximum and minimum temperature are performed during baseline (1961-1990) period and 2000-2006 respectively (not shown). Fig. (10) shows the annual cycle of baseline temperature obtained by model and observation (normal) with projected temperature for 2010-2020. During the baseline period, model under-calculated maximum temperature (Fig. 10a). However, after calibration, projected temperature will follow the historical trend. On the other hand model over-calculated minimum temperature (Fig. 10b) during baseline period from March to September and under-calculated from October to February. Again, after calibration the projected minimum temperature will follow the historical trend. This indicates the importance of calibration of model outputs with observed data for a particular region, especially for application purposes.

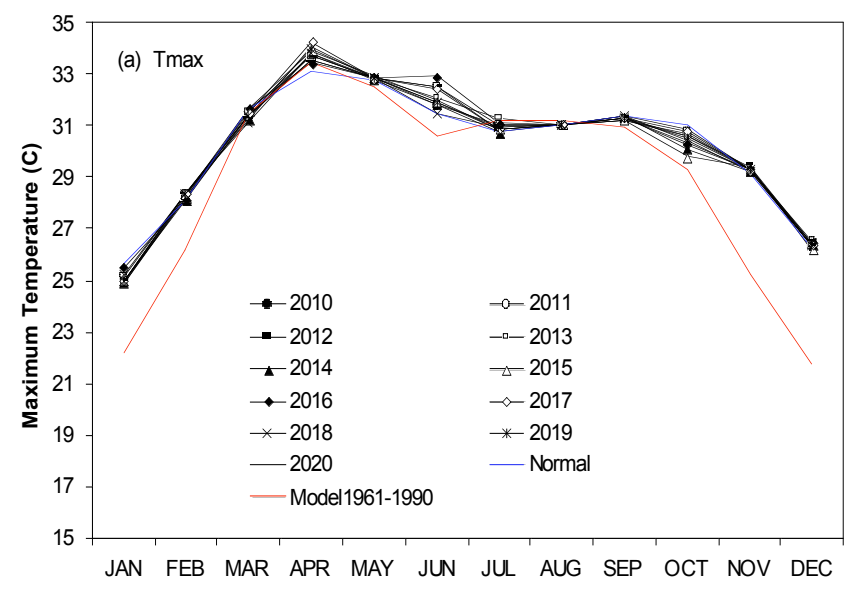

Fig. (10a). Annual variation of calibrated maximum temperature $\left({ }^{\circ} \mathrm{C}\right)$ during baseline period and projected by PRECIS. Model notcalibrated maximum temperature during 1961-1990 is shown with observed historical normal.

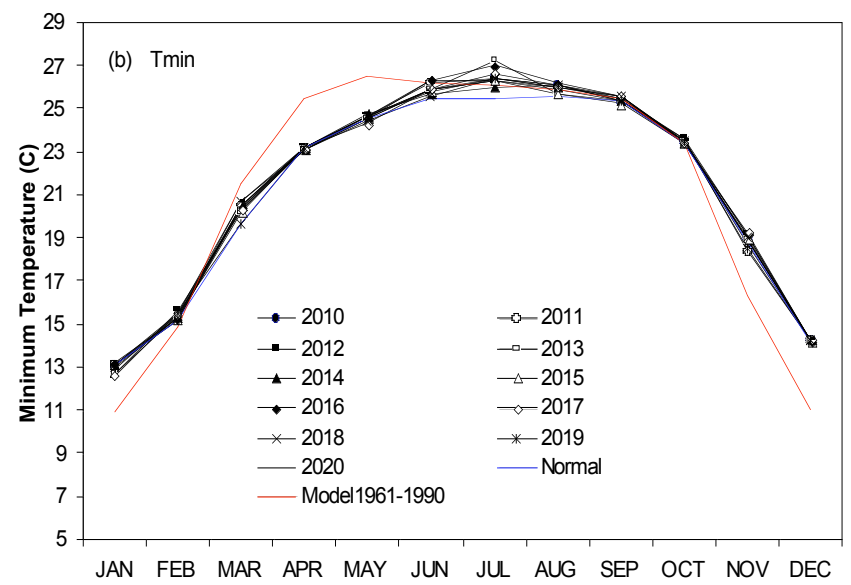

Fig. (10b). The same as Fig. (10a) except for minimum temperature.

\section{DISCUSSION}

In order to obtain the performance of PRECIS modeling system in Bangladesh, simulated outputs are needed to be calibrated and validated with ground-based observed datasets. In previous section the calibration of PRECIS outputs are performed with observed datasets for the baseline period (1961-1990) in Bangladesh. Validating PRECIS generated rainfall, TRMM V6 3B42 datasets is used to see the overall model performance in 2002. TRMM derived rainfall can be considered as the ground-truth amount even it scans from the upper side of the convective systems. The TRMM measured rainfall is already calibrated with ground-based rain-gauge rainfall in Bangladesh (Islam and Uyeda [17]). It is found that TRMM is able to catch about $97 \%$ of the surface rain. The distribution of TRMM derived annual rainfall $(\mathrm{mm} / \mathrm{d})$ in the SAARC domain for 2002 is shown in Fig. (11a). The idea is that, how much rainfall could be generated by PRECIS, at least in qualitatively because calibration fac- 
Table 3. Projection of Rainfall $(\mathrm{mm} / \mathrm{d})$ in Bangladesh Obtained by the PRECIS Model

\begin{tabular}{|c|c|c|c|c|c|c|c|c|c|c|c|c|c|}
\hline Year & $\mathbf{2 0 0 9}$ & $\mathbf{2 0 1 0}$ & $\mathbf{2 0 1 1}$ & $\mathbf{2 0 1 2}$ & $\mathbf{2 0 1 3}$ & $\mathbf{2 0 1 4}$ & $\mathbf{2 0 1 5}$ & $\mathbf{2 0 1 6}$ & $\mathbf{2 0 1 7}$ & $\mathbf{2 0 1 8}$ & $\mathbf{2 0 1 9}$ & $\mathbf{2 0 2 0}$ & Normal \\
\hline \hline Rainfall & 6.92 & 7.10 & 6.90 & 7.13 & 6.71 & 6.73 & 6.93 & 6.86 & 6.91 & 7.16 & 7.00 & 6.83 & 6.78 \\
\hline
\end{tabular}

tor could be utilized to obtain the quantitative amounts. In this connection annual rainfall $(\mathrm{mm} / \mathrm{d})$ simulated by PRECIS for 2002 is presented in Fig. (11b). The patterns of rainfall obtained by TRMM and PRECIS are somehow quite similar, especially heavy rainfall in the NE of Bangladesh, Western Ghat of India and a long band along Nepal. The no-rain tongue in the eastern side of Western Ghat of India is not observed in TRMM derived rainfall. This indicates that the distributions of model simulated rainfall patterns are more or less similar. The model was run in $50 \mathrm{~km}$ horizontal resolution whereas TRMM product is about $25 \mathrm{~km}$ in horizontal resolution. Therefore, high resolution PRECIS run may also be considered in future work.

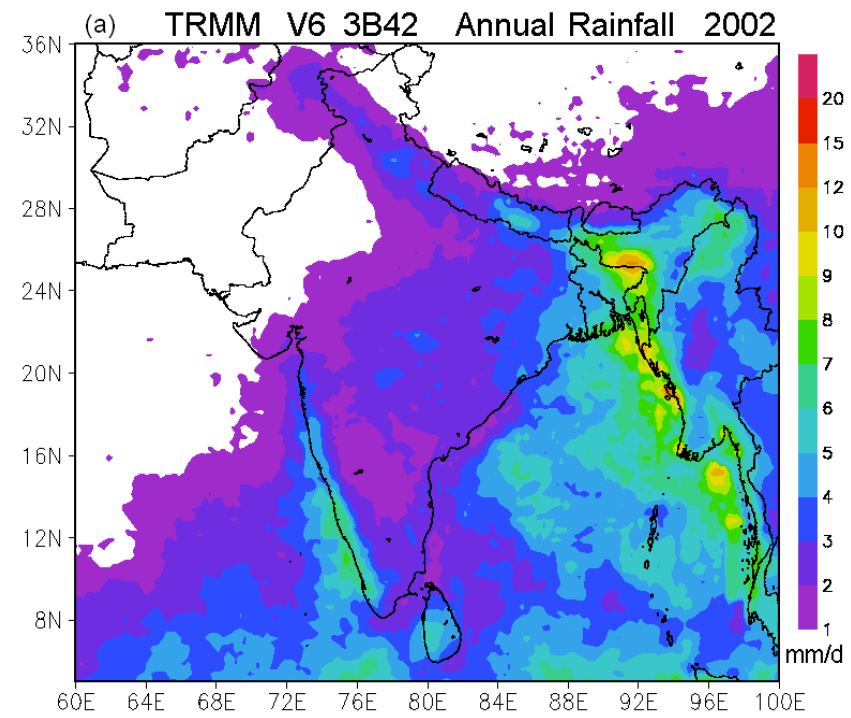

Fig. (11a). Annual rainfall (mm/d) derived from TRMM V6 3B42 for 2002 .

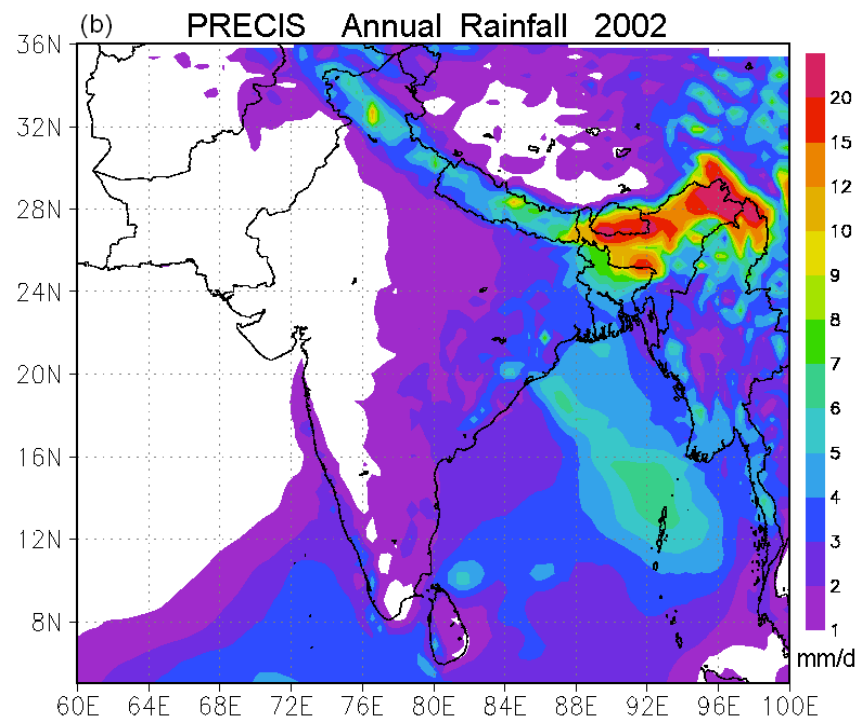

Fig. (11b). Annual rainfall (mm/d) derived from PRECIS simulation for 2002.

\section{Calibration and Validation}

As mentioned earlier, validation of model simulated rainfall is only closer to observed value when regression constants and slopes are utilized with model outputs. In this connection, regression coefficients of Eq. (1) calculated at each station for different months are presented in Tables 4 and 5.

In order to understand the model performance, scatter plot of monthly rainfall $(\mathrm{mm} / \mathrm{d})$ obtained from both model estimation and observation for 2000 - 2006 is shown in Fig. (12). The slope is 0.90 and the correlation coefficient is 0.90 in annual scale. These values are poor (not shown) for individual months. This indicates that after performing the calibration, model estimated rainfall is reasonably consistent with the observed data in annual scale. Hence, the result encourages in utilizing PRECIS for forecasting annual rainfall in Bangladesh. The extended work is ongoing for the entire SAARC domain for more clarifications.

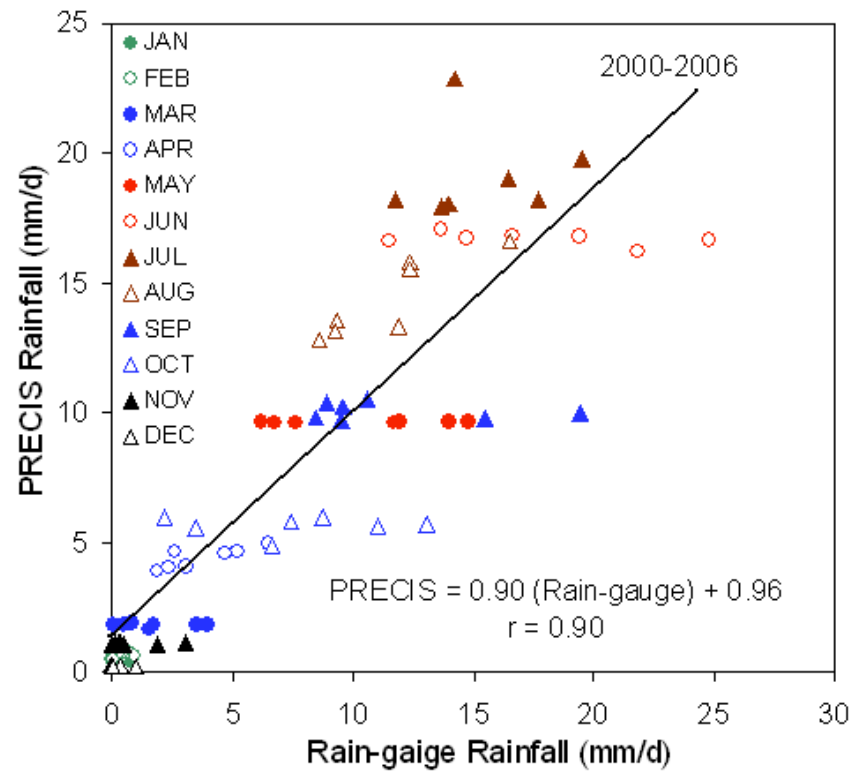

Fig. (12). Scatter plot of monthly model rainfall $(\mathrm{mm} / \mathrm{d})$ versus rain-gauge rainfall at different months during 2000-2006.

\section{Projection of Rainfall}

Regression constants and slopes are utilized with model simulated outputs in obtaining rainfall projection in Bangladesh for $2010-2020$. The projected JJAS rainfall $(\mathrm{mm} / \mathrm{d})$ for calibrated and not-calibrated is shown in Fig. (13a). After calibration the variation of JJAS rainfall is reduced. One can calculate the standard deviation of JJAS rainfall to 1.79 and 1.71 for observed and model not-calibrated respectively during 1961-1990. The values are 1.56 and 0.85 for model notcalibrated and model calibrated respectively during validation phase 2000-2006. For projection, the values are 2.19 and 0.35 for not-calibrated and calibrated respectively during 2010-2020. 


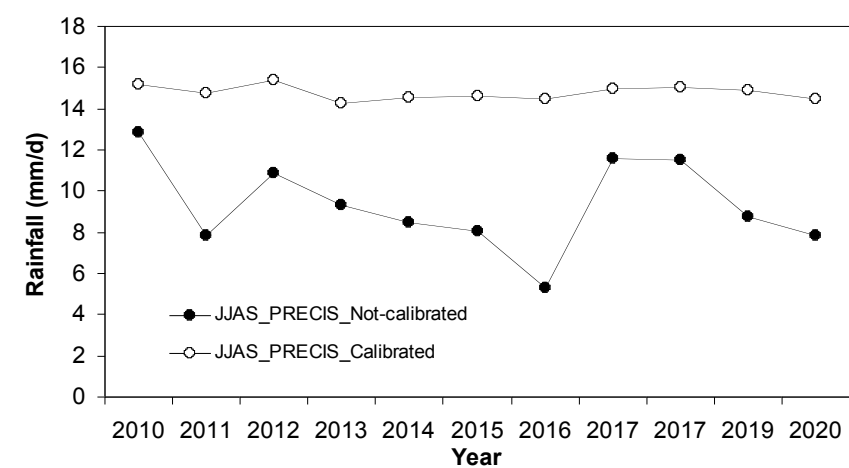

Fig. (13a). JJAS calibrated and not-calibrated rainfall $(\mathrm{mm} / \mathrm{d})$ during 2010 - 2020 for Bangladesh.

The change of model calibrated annual rainfall (\%) up-to the year 2020 is shown in Fig. (13b). Rainfall will surplus in all years except for 2013 and 2014. The change lies between about $+5.3 \%$ (in 2018) to $-1 \%$ (in 2013). The cause of surplus and deficit is not the aim of this work. However, the idea about long-term rainfall forecast is the goal of this study which is needed to the planners and stakeholders of the country.

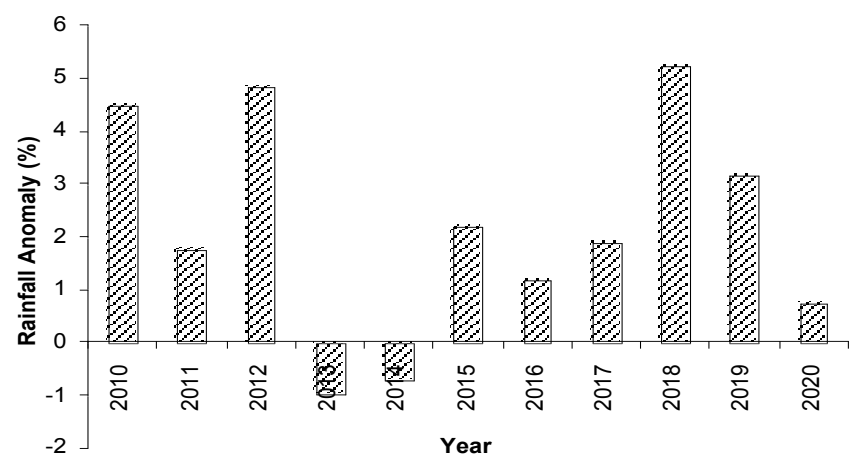

Fig. (13b). Change of rainfall (\%) during 2010 - 2020 for Bangladesh.

Table 4. Regression Constants in Different Months and at Different Observational Sites over Bangladesh

\begin{tabular}{|c|c|c|c|c|c|c|c|c|c|c|c|c|}
\hline & JAN & FEB & MAR & APR & MAY & JUN & JUL & AUG & SEP & OCT & NOV & DEC \\
\hline Barishal & 0.27 & 0.69 & 1.88 & 2.86 & 6.95 & 10.19 & 13.55 & 5.00 & 10.40 & 7.82 & 0.81 & 0.36 \\
\hline Bogra & 0.52 & 0.42 & 0.47 & 2.20 & 7.64 & 6.11 & 4.40 & 14.57 & 7.74 & 4.26 & 0.51 & 0.06 \\
\hline Chandpur & 0.55 & 0.43 & 2.79 & 4.40 & 12.34 & 6.64 & 9.59 & 4.43 & 9.45 & 6.76 & 1.18 & 0.09 \\
\hline Comilla & 0.29 & 0.37 & 1.68 & 4.37 & 9.18 & 10.08 & 8.32 & 16.17 & 9.31 & 6.14 & 0.98 & 0.13 \\
\hline Cox's Bazar & 0.45 & 0.71 & 2.88 & 6.99 & 24.82 & 40.51 & 12.61 & 10.04 & 7.80 & 3.65 & 0.34 & 0.20 \\
\hline Dhaka & 0.29 & 0.69 & 2.17 & 4.05 & 12.56 & 11.09 & 13.35 & 9.94 & 8.00 & 4.86 & 0.92 & 0.29 \\
\hline Dinajpur & 0.70 & 0.27 & 0.52 & 1.88 & 6.88 & 8.43 & 6.40 & 6.71 & 10.79 & 3.06 & 0.14 & 0.07 \\
\hline Jessore & 0.54 & 0.93 & 1.61 & 1.77 & 4.49 & 7.43 & 14.24 & 4.68 & 9.91 & 5.55 & 0.68 & 0.22 \\
\hline Khepupara & 0.64 & 0.94 & 1.49 & 2.05 & 6.23 & 8.00 & 24.90 & 12.68 & 15.17 & 7.46 & 1.83 & 0.23 \\
\hline Khulna & 0.19 & 0.79 & 1.65 & 2.22 & 6.20 & 9.13 & 18.40 & 8.94 & 11.75 & 4.97 & 0.75 & 0.09 \\
\hline Kutubdia & 0.27 & 0.58 & 2.68 & 2.59 & 2.02 & 47.05 & 14.88 & 2.07 & 6.61 & 5.45 & 2.19 & 0.21 \\
\hline Maijdi Court & 0.25 & 0.91 & 1.43 & 3.57 & 10.45 & 14.76 & 22.26 & 14.30 & 8.21 & 8.62 & 1.43 & 0.34 \\
\hline Mymensingh & 0.40 & 0.58 & 1.26 & 2.31 & 7.10 & 19.23 & 21.61 & 10.99 & 6.99 & 7.05 & 0.55 & 0.04 \\
\hline Patuakhali & 0.81 & 0.74 & 1.41 & 3.37 & 11.57 & 11.10 & 18.27 & 12.77 & 18.70 & 5.88 & 2.37 & 0.33 \\
\hline Rajshahi & 0.69 & 0.54 & 1.03 & 0.67 & 4.20 & 11.80 & 10.79 & 4.55 & 8.26 & 4.96 & 0.29 & 0.20 \\
\hline Sylhet & 0.88 & 2.33 & 3.66 & 6.97 & 19.36 & 36.30 & 27.18 & 18.84 & 12.86 & 8.06 & 0.98 & 0.15 \\
\hline Teknaf & 0.57 & 0.33 & 0.29 & 2.41 & 5.76 & 28.61 & 24.58 & 22.42 & 10.21 & 5.68 & 2.18 & 0.17 \\
\hline
\end{tabular}


Table 5. Regression Slopes in Different Months and at Different Observational Sites over Bangladesh

\begin{tabular}{|c|c|c|c|c|c|c|c|c|c|c|c|c|}
\hline & JAN & FEB & MAR & APR & MAY & JUN & JUL & AUG & SEP & OCT & NOV & DEC \\
\hline Barishal & 0.25 & 0.06 & -0.18 & 0.26 & 0.01 & 0.21 & -0.11 & 1.00 & -0.16 & -0.46 & 0.63 & 0.19 \\
\hline Bhola & 0.73 & -1.13 & 0.49 & 0.41 & -0.23 & 0.15 & 0.94 & -0.16 & 0.12 & -0.26 & 0.24 & -0.23 \\
\hline Bogra & -0.18 & -0.03 & 0.07 & 0.02 & -0.11 & 0.36 & 1.40 & -0.90 & 0.07 & -0.05 & -0.04 & 0.36 \\
\hline Chandpur & 0.01 & -0.15 & -0.37 & 0.47 & -0.33 & 0.50 & 0.60 & 0.99 & -0.17 & -0.61 & -0.05 & 0.42 \\
\hline Chittagong & 0.03 & 0.30 & -0.23 & 0.42 & 0.26 & 0.17 & -1.12 & 1.13 & -0.17 & -0.19 & -0.09 & -0.12 \\
\hline Comilla & 0.14 & 0.18 & -0.10 & 0.23 & -0.03 & 0.21 & 0.82 & -0.67 & -0.17 & -0.25 & 0.31 & 0.14 \\
\hline Cox's Bazar & 0.32 & -0.01 & 0.58 & 0.31 & 0.09 & -0.27 & 0.80 & 0.21 & 0.01 & -0.03 & 0.02 & -0.02 \\
\hline Dhaka & 0.10 & 0.11 & -0.19 & 0.33 & -0.28 & 0.12 & -0.16 & -0.01 & 0.29 & 0.06 & 0.31 & -0.02 \\
\hline Dinajpur & -0.74 & -0.11 & 0.21 & 0.04 & -0.07 & 0.26 & 1.14 & 0.63 & -0.14 & 0.10 & 0.19 & 0.55 \\
\hline Faridpur & 0.11 & -0.18 & -0.40 & 0.39 & -0.01 & -0.16 & 0.74 & 0.32 & 0.61 & 0.10 & 0.18 & 0.14 \\
\hline Hatiya & 0.18 & -0.02 & 0.03 & 0.33 & -0.10 & -0.14 & -0.10 & 0.39 & 0.27 & 0.00 & 0.11 & -0.11 \\
\hline Ishurdi & -0.03 & -0.08 & -0.24 & 0.50 & -0.01 & -0.88 & 0.64 & 0.28 & 0.63 & -0.30 & -0.02 & 0.09 \\
\hline Jessore & 0.06 & -0.17 & -0.20 & 0.42 & 0.02 & 0.25 & -0.63 & 0.72 & -0.31 & -0.27 & 0.19 & 0.44 \\
\hline Khepupara & 0.02 & -0.38 & -0.12 & 0.50 & 0.08 & 0.27 & -0.41 & 0.19 & -0.25 & -0.17 & -0.02 & -0.05 \\
\hline Khulna & 0.38 & -0.24 & -0.25 & 0.47 & -0.02 & 0.21 & -0.81 & 0.18 & -0.53 & -0.26 & 0.05 & 0.20 \\
\hline Kutubdia & -0.09 & -0.20 & -0.52 & -0.11 & 0.22 & -1.48 & 0.57 & 1.01 & 0.35 & -0.29 & -0.08 & -0.04 \\
\hline Maidi Court & 0.68 & -0.26 & 0.08 & 0.18 & -0.01 & 0.16 & 0.35 & 1.13 & 0.74 & -0.49 & 0.13 & -0.05 \\
\hline Mymensingh & 0.01 & 0.02 & -0.05 & 0.22 & 0.28 & -0.52 & -1.20 & -0.13 & 0.50 & -0.35 & 0.02 & 0.26 \\
\hline Patuakhali & -0.06 & -0.15 & -0.59 & 0.35 & -0.17 & 0.38 & -0.10 & 0.22 & -0.60 & -0.26 & 0.33 & -0.24 \\
\hline Rajshahi & -0.10 & -0.06 & -0.14 & 0.44 & 0.00 & -0.23 & 0.10 & 0.79 & 0.02 & -0.20 & 0.16 & 0.20 \\
\hline Rangamati & -0.04 & -0.10 & 0.01 & 0.58 & 0.13 & -0.24 & -1.74 & 0.20 & -0.74 & -0.24 & -0.04 & -0.17 \\
\hline Rangpur & -0.27 & -0.07 & 0.35 & 0.09 & -0.04 & 0.09 & 1.29 & 0.48 & 0.00 & -0.03 & 0.01 & 0.43 \\
\hline Sandwip & 0.17 & 0.21 & -0.12 & 0.46 & -0.05 & 0.04 & -0.06 & 0.16 & 0.71 & -0.09 & 0.23 & 0.00 \\
\hline Sitakunda & 0.03 & -0.13 & -0.64 & 0.03 & -0.27 & 0.03 & -0.25 & 4.33 & 0.69 & -0.87 & 0.02 & 0.21 \\
\hline Srimongal & -0.30 & -0.03 & -0.05 & 0.44 & -0.17 & -0.55 & 1.30 & 0.56 & 0.72 & -0.82 & 0.21 & -0.09 \\
\hline Sylhet & -0.19 & -0.19 & 0.02 & 0.22 & -0.03 & -0.39 & -0.05 & 0.14 & 0.38 & -0.09 & 0.04 & 0.05 \\
\hline Teknaf & 0.03 & -0.15 & -0.06 & 0.14 & 0.02 & 0.09 & 0.40 & 0.27 & 0.41 & -0.13 & 0.45 & 0.03 \\
\hline
\end{tabular}

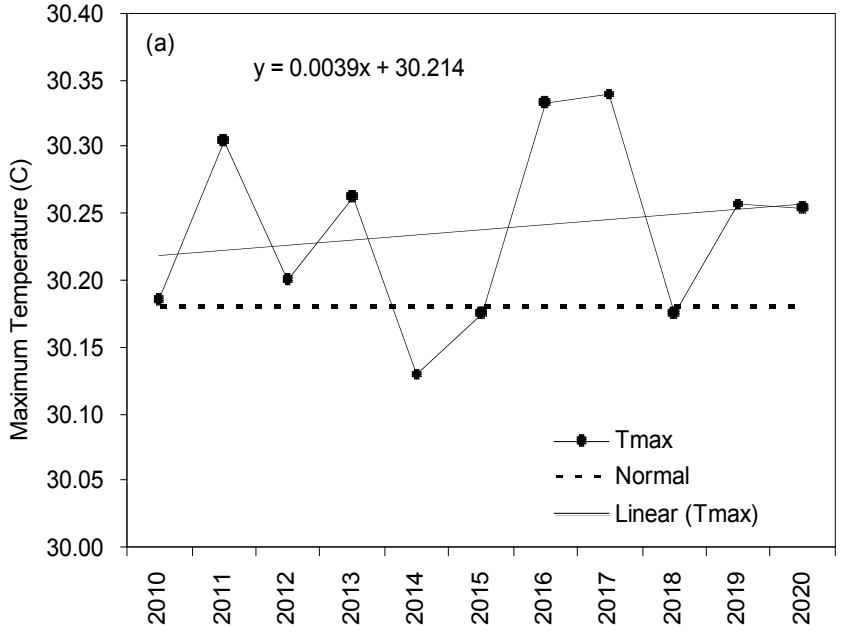

Fig. (14a). Maximum temperature $\left({ }^{\circ} \mathrm{C}\right)$ projected by PRECIS.

\section{Projection of Temperature}

Projected maximum and minimum temperature during 2010-2020 for Bangladesh are shown in Fig. (14). The dashed line indicates the historical normal. Maximum temperature (Fig. 14a) will increase in a rate of about $0.004{ }^{\circ} \mathrm{C}$ per year while the increase rate of minimum temperature (Fig. 14b) is almost half $\left(0.002{ }^{\circ} \mathrm{C}\right)$ compared to that of maximum temperature. Importantly, difference of minimum temperature from normal is large compared to the same for maximum temperature.

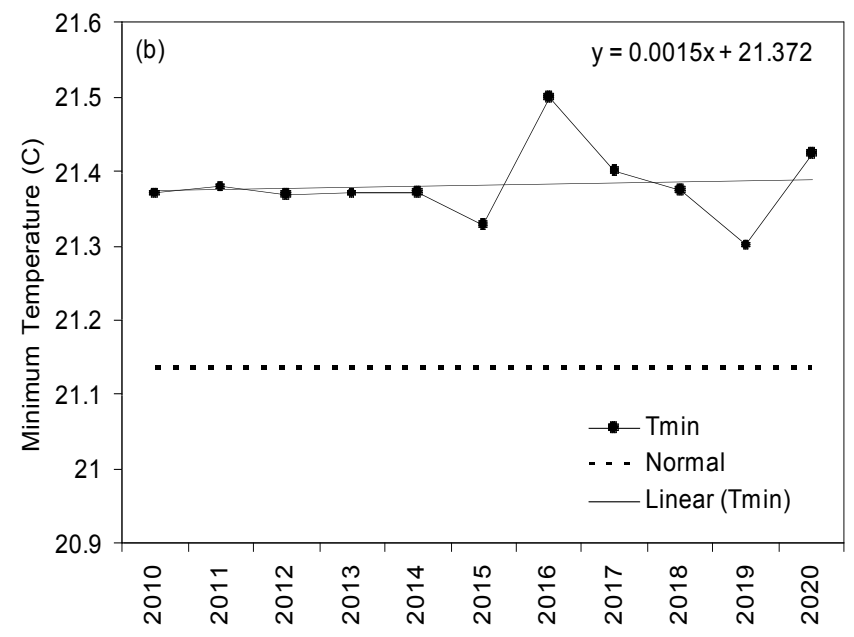

Fig. (14b). Minimum temperature $\left({ }^{\circ} \mathrm{C}\right)$ projected by PRECIS. 


\section{CONCLUSIONS}

A regional climate model named PRECIS is employed in generating rainfall and temperature scenarios for SAARC region. PRECIS generated rainfall and temperature scenarios are calibrated with ground-based observed data during 19611990 in Bangladesh. Through calibration, regression coefficients such as slopes and constants are obtained at 27 observational sites over Bangladesh. The regression coefficients are utilized in validation of PRECIS generated rainfall and temperature during 2000 to 2006 . Better performance of PRECIS through validation encourages employing it in rainfall and temperature forecasting for Bangladesh. In this work, rainfall and temperature forecast for Bangladesh is performed experimentally for 2010-2020. In 2009, the monsoon rainfall is projected with of surplus $0.29 \mathrm{~mm} / \mathrm{d}(2.03 \%)$ and it will be surplus by $0.44 \mathrm{~mm} / \mathrm{d}(14.02 \%)$ in postmonsoon. It will be deficit by $0.11 \mathrm{~mm} / \mathrm{d}(2.08 \%)$ and 0.01 $\mathrm{mm} / \mathrm{d}(1.44 \%)$ in pre-monsoon and dry season respectively. During 2009-2020, the change of rainfall is projected between about $+5.3 \%$ (in 2018) to $-1 \%$ (in 2013). Through the analysis of monsoon rainfall in Bangladesh, this work discloses that PRECIS simulated rainfall is not directly useful in application purposes. Without calibration with groundtruth data, model outputs are very risky in providing longterm rainfall prediction. However, after performing calibration acceptable result is obtained in estimating rainfall in Bangladesh with correlation is 0.90 . The monsoon rainfall forecasting approach using downscaling of regional climate model outputs is very new in Bangladesh. This result suggests for extending the work for other SAARC countries in a consecutive research project. Model run with other ensembles and with high horizontal resolution are also under consideration.

\section{ACKNOWLEDGEMENTS}

The author is grateful to the Hadley Centre of the United Kingdom Meteorological Office for providing the PC-based PRECIS model with LBC data. The Bangladesh Meteorological Department (BMD) is acknowledged for providing rain-gauge data. Climate Change Cell, Government of the People's Republic of Bangladesh supported the calibration part of the work. The author acknowledges Md. Abdul Mannan of BMD and Md. Mizanur Rahman of SMRC for their valuable help in observational data processing and David Hein of UK Meteorological Office for providing technical support. The TRMM 3B42 data are collected from TRMM website.

\section{REFERENCES}

[1] Huq S, Karim Z, Asaduzzaman M and Mahtab F, Eds. Vulnerability and adaptation to climate change for Bangladesh, Kluwer Academic Publishers, Dordrecht 1998; p. 135.

[2] Karim Z, Hussain SkG, Ahmed AU. Climate change vulnerability of crop agriculture. In: Huq S, Karim Z, Asaduzzaman M, Mahtab F, Eds. Vulnerability and adaptation to climate change for Bangladesh, Kluwer Academic Publishers, Dordrecht 1998.

[3] Ali A. Climate change impacts and adaptation assessment in Bangladesh. Climate Res 1999; 12: 109-16.

[4] Houghton JT, Ding Y, Griggs DJ, Noguer M, van der Linden PJ, Xioaosu D, Eds. Climate Change 2001: The Scientific Basis, Contribution of Working Group I to the Third Assessment Report of the Intergovernmental Panel on Climate Change. Cambridge University Press, Cambridge 2001.

[5] Houghton JT, Meira FLG, Callander BA, Harris N, Kattenberg A, Maskell K, Eds. Clim Change: Intergovernmental Panel on Climate Change (IPCC), Cambridge University Press, Cambridge 1995.

[6] McCarthy JJ, Canziani OF, Leary NA, Dokken DJ, White KS, Eds. Climate Change 2001: Impacts, Adaptation. and Vulnerability, Inter-Governmental Panel on Climate Change (IPCC), Work Group II Input to the Third Assessment Report, Cambridge University Press, Cambridge, 2001.

[7] McGuffie K, Henderson-Sellers A. A climate modelling primer, John Wiley \& Sons 1997.

[8] Murphy JM, Mitchell JFB. Transient response of the Hadley Centre coupled ocean-atmosphere model to increasing carbon dioxide. Part II. Spatial and temporal structure of response. J Climate 1995; 8: 57-80.

[9] Dickinson R, Errico R, Giorgi F, Bates G. A regional climate model for the Western United States. Clim Change 1989; 14(3): 383-422.

[10] Hack J, Boville B, Briegleb B, Kiehl J, Tasch P, Williamson D. Description of the NCAR community climate model (CCM2). Technical report, National Center for Atmospheric Research (NCAR), Colorado 1993.

[11] Grell G, Dudhia J, Stauffer D. A description of the fifth-generation penn state/NCAR mesoscale model (MM5). Technical Note TN398+IA, Technical report, National Center for Atmospheric Research (NCAR), Colorado 1994.

[12] Robinson PJ, Finkelstein PL. The development of impact oriented climate scenarios. Bull Am Meteorol Soc 1991; 72: 481-90.

[13] Jones RG, Noguer M, Hassell DC, et al., Generating high resolution climate change scenarios using PRECIS, Met Office Hadley Centre, Exeter, UK 2004.

[14] Georgi F, Hewitson B. Regional Climate Information - Evaluation and Projections. In: Houghton JT, Ding Y, Griggs DJ, Noguer M, van der Linden PJ, Xioaosu D, Eds. Climate Change: The Scientific Basis, Contribution of Working Group I to the Third Assessment Report of the Intergovernmental Panel on Climate Change, Cambridge University Press, Cambridge 2001.

[15] Simmons AJ, Burridge DM. An energy and angular-momentum conserving finite-difference scheme and hybrid coordinates. Monthly Weather Rev 1981; 109: 758-66.

[16] Simon W, Hassell D, Hein D, Jones R, Taylor R. Installing and using the Hadley Centre regional climate modelling system, PRECIS, Version 1.1, Met Office Hadley Centre, Exeter, UK 2004.

[17] Islam Nazrul M, Rafiuddin M, Ahmed AU, Kolli RK. Calibration of PRECIS in employing future scenarios in Bangladesh. Int J Climatol, Wiley InterScience 2008; 8: 617-28, doi: 10.1002/joc. 1559. Islam Nazrul M, Uyeda H. Use of TRMM in determining the climatic characteristics of rainfall over Bangladesh. Remote Sens Environ Elsevier Inc 2007; 108(3): 264-76. doi:10.1016/j.rse. 2006.11.011. 